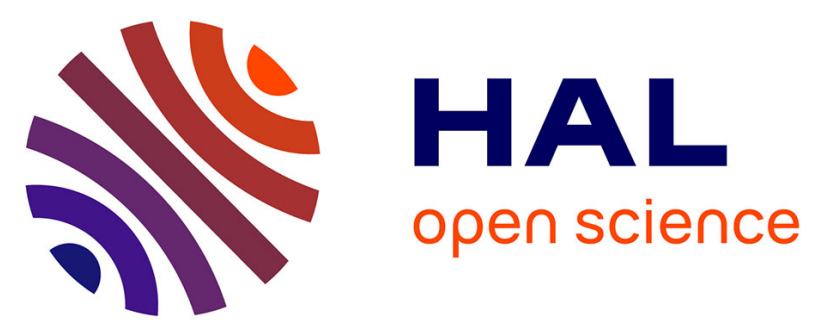

\title{
Isolation and purification treatments change the metal-binding properties of humic acids: effect of $\mathrm{HF} / \mathrm{HCl}$ treatment
}

Wander G. Botero, Michael Pineau, Noémie Janot, Rute F. Domingos, José

Mariano, Luciana S. Rocha, Jan E. Groenenberg, Marc F. Benedetti, José P.

Pinheiro

\section{To cite this version:}

Wander G. Botero, Michael Pineau, Noémie Janot, Rute F. Domingos, José Mariano, et al.. Isolation and purification treatments change the metal-binding properties of humic acids: effect of $\mathrm{HF} / \mathrm{HCl}$ treatment. Environmental Chemistry, 2017, 14 (7), pp.417-424. 10.1071/EN17129 . hal-02627272

\section{HAL Id: hal-02627272 \\ https://hal.inrae.fr/hal-02627272}

Submitted on 11 Oct 2021

HAL is a multi-disciplinary open access archive for the deposit and dissemination of scientific research documents, whether they are published or not. The documents may come from teaching and research institutions in France or abroad, or from public or private research centers.
L'archive ouverte pluridisciplinaire HAL, est destinée au dépôt et à la diffusion de documents scientifiques de niveau recherche, publiés ou non, émanant des établissements d'enseignement et de recherche français ou étrangers, des laboratoires publics ou privés.

\section{(ㅇ)(1) $\$$}

Distributed under a Creative Commons Attribution - NonCommercial - NoDerivatives 44.0 


\section{Isolation and purification treatments change the metal- binding properties of humic acids: effect of $\mathrm{HF} / \mathrm{HCl}$}

\section{treatment}

Wander G. Botero ${ }^{1, *}$, Michael Pineau' ${ }^{2}$,Noémie Janot ${ }^{3}$, Rute F. Domingos ${ }^{4}$, José Mariano ${ }^{5}$, Luciana S. Rocha' ${ }^{2}$ Jan E. Groenenberg ${ }^{3,6}$, Marc F. Benedetti ${ }^{4}$, José P. Pinheiro ${ }^{3}$

${ }^{1}$ Federal University of Alagoas (UFAL), Campus Arapiraca, 57309-005, Arapiraca, AL, Brazil

${ }^{2}$ Department of Chemistry and Biochemistry/Faculty of Science and Technology, University of Algarve, Campus de Gambelas, 8005-139 Faro, Portugal

${ }^{3}$ LIEC, UMR7360, Université de Lorraine/CNRS 15 Avenue du Charmois, Vandœuvre-lès-Nancy F-54501, France

${ }^{4}$ IPGP, Sorbonne Paris Cité, Université Paris Diderot, UMR CNRS 7154, 75205 Paris Cedex 05, France.

${ }^{5}$ Department of Physics and CeFEMA, Faculty of Science and Technology, University of Algarve, Campus de Gambelas, Faro 8005-139, Portugal.

${ }^{6}$ Department of Soil Quality, Wageningen University and Research, PO Box 47, 6700 AA Wageningen, The Netherlands.

* corresponding author e-mail : wanderbotero@gmail.com

Environmental context. Studying the mechanism of binding between metals and natural organic matter is fundamental to understanding the transport and availability of these contaminants in the environment. The influence of sample treatment on the purification of organic matter showed significant differences in the interaction with metals. The results will contribute to improved modelling of metal binding to organic matter in soils, thereby providing a basis for a more realistic risk assessment.

ABSTRACT. We studied the changes in metal binding characteristics of extracted humic acids induced by $\mathrm{HF} / \mathrm{HCl}$ treatment followed by dialysis, i.e. the last step of the International Humic Substances Society (IHSS) extraction protocol. We performed metal binding experiments with both the alkaline-extracted material (AE) and the fully purified (FP) humic acid using the electrochemical stripping technique (AGNES) and modelled the results using the NICA-Donnan model. The results showed an increase of free $\mathrm{Zn}, \mathrm{Cd}$ and $\mathrm{Pb}$ concentrations of ,1 order of magnitude for the $\mathrm{AE}$ compared with the FP. These differences may be mostly explained by the different carbon content $(51.3 \%$ FP and $36.5 \% \mathrm{AE}$ ) associated with an AE/FP carboxyl ratio of 0.5. Simulations using the NICA-Donnan model showed that halving the amount of carboxylic groups (Qmax,1) for the FP reduced this difference to $0.25 \log$ units for $\mathrm{Cd}$ and $\mathrm{Zn}$ and to $0.15 \mathrm{log}$ unit for $\mathrm{Pb}$. There is a clear need for further research on the differences between purified v. less-disturbed natural organic material, which will contribute to improved modelling of metal binding to organic matter in soils, hence providing a basis for a more realistic risk assessment.

KEYWORDS Alkaline-extracted material, humic acid 


\section{Introduction}

The solid solution partitioning and speciation of trace metals in terrestrial and aquatic environments is key to understanding their mobility, fate and bioavailability. During the last decades, great progress has been made in the development of advanced speciation models for the prediction of metal binding to the most important adsorbing constituents in natural systems, such as organic matter, $\mathrm{Al}, \mathrm{Fe}$ and Mn-(hydr)oxides, clays and their assemblages ${ }^{[1]}$. Areas of applications of these models include: (i) environmental fate ${ }^{[2,3]}$ (ii) ecotoxicity ${ }^{[4]}$ and metal deficiency in micronutrients ${ }^{[5]}$ and (iii) environmental risk assessment and regulation $^{[6-8]}$.

Experimental and modelling studies indicate a prominent role of organic matter (OM) in metal binding in soils and surface waters ${ }^{[1,9,10]}$. The most advanced models for metal binding to organic matter, especially the alkaline extract or 'humic fraction' thereof, are the Humic Ion Binding Models VII[11], the Stockholm Humic Model (SHM) ${ }^{[12]}$ and the Non-Ideal Competitive Adsorption-Donnan (NICA-Donnan) model ${ }^{[13]}$. Model parameters are derived from proton and metal binding experiments with purified humic and fulvic acids isolated from soils and surface waters in general using the extraction procedures suggested by the International Humic Substances Society (IHSS). However, besides the humic substances, other ligands of a more hydrophilic nature (including biological exudates and low-molecular organic acids) may have a role in the speciation of metals in terrestrial and aquatic systems ${ }^{[14-16]}$.

Thus, there are questions regarding the representativeness of purified humic substances for OM in natural systems, especially in soils where the extraction procedure includes an $\mathrm{HF} / \mathrm{HCl}$ attack to destroy the more resistant aluminosilicate minerals. It has been suggested that the harsh chemical conditions of the soil humic substances isolation and purification may cause artefacts that influence their binding properties ${ }^{[17]}$, and that configurational aspects and interactions with inorganic colloidal materials leading to the formation of heteroaggregates may affect the binding properties of the humic materials ${ }^{[18]}$. The purification of aquatic humic matter is considerably softer from the chemical point of view and thus less criticised. Amongst other work, Ahmed et al. ${ }^{[19]}$ recently compared metal binding to aquatic humic acid (HA) and fulvic acid (FA) isolated according to the IHSS protocol with dissolved OM obtained by a milder procedure and found similar behaviour.

Geochemical modelling studies have shown that only a fraction of soil OM can be interpreted in concentrations of 'reactive' OM with equivalent binding properties to isolated and purified FA and HA. Several studies have related this fraction of reactive $\mathrm{OM}$ in soil with the extractable humic substances. The results vary depending on the types of soils; for example, Dijkstra et al. ${ }^{[20]}$ reported a fraction of extracted humic substances from eight sandy soils between 25 and $67 \%$ of the total soil OM, whereas Lumsdon ${ }^{[21]}$ obtained values between 14 and $87 \%$ for seven different soils, being the lowest extraction in the O-horizon of forest soil. Weng et al. ${ }^{[22]}$ used cation exchange capacity measurements to estimate that the average binding site density of a sandy soil is $36 \%$ of that corresponding to the generic HA. Lopez et al. ${ }^{[23]}$ measured the acid-base properties of a peat soil and its humin, HA and FA fractions and concluded that the proton-binding properties of the peat soil are analogous to those of the humin, whereas the soil showed only $41 \%$ of carboxylic groups but an identical amount of phenolic groups when compared with the dissolved HA.

Another interesting trend is the growing interest of agro-industry in selling alkaline soil OM extracts, especially those obtained from peat soils, as natural fertilisers to replace commercially used inorganic fertilisers. The commercial version of the 'natural fertilisers' is usually available in the form of 'humic substances' or 'humic acid', their purification being similar to the IHSS procedure ${ }^{[24]}$ but without $\mathrm{HCl} / \mathrm{HF}$ treatment and dialysis. The environmental impact of these fertilisers is thus difficult to model because the extraction and purification procedures are different from the ones used in the scientific studies that have as their objective obtaining model parameters ${ }^{[25]}$.

The hypothesis of the present work is that the $\mathrm{HF} / \mathrm{HCl}$ treatment followed by dialysis in the last step of the IHSS extraction protocol effectively changes the metal-binding characteristics of the 
extracted organic matter, and that this may have a significant impact on predicted metal speciation in risk assessment studies.

To investigate this hypothesis, we measured the free zinc, lead and cadmium concentrations in the presence of humic matter, taking advantage of the nanomolar detection limit of the electrochemical stripping technique (absence of gradients and Nernstian equilibrium stripping, AGNES). The results are interpreted and discussed within the framework of the NICA-Donnan model. It is the first time that zinc-binding properties with humic matter at such low metal concentrations are presented, while lead and cadmium measurements are useful for comparison with previously published parameters.

\section{Materials and methods}

\subsection{Chemicals and reagents}

The chemicals used were of analytical reagent grade and were used as received. All solutions were prepared with ultrapure water $(18.3 \mathrm{MO} \mathrm{cm}$, Milli-Q systems, Millipore-Waters, USA). Nitric acid (65\%, Suprapur) and standard stock solutions of mercury nitrate $\left(1001 \pm 2 \mathrm{mg} \mathrm{L}^{-1}\right)$, cadmium nitrate $\left(999 \pm 2 \mathrm{mg} \mathrm{L}^{-1}\right)$, lead nitrate $(999 \pm$ $\left.2 \mathrm{mg} \mathrm{L}^{-1}\right)$ and zinc nitrate $\left(999 \pm 2 \mathrm{mg} \mathrm{L}^{-1}\right)$ were purchased from Merck. Sodium nitrate electrolyte solution (0.01 M), MES (2-(N-morpholino)ethanesulfonic acid) and MOPS (3-(Nmorpholino)propanesulfonic acid) buffer solutions were prepared from the solids (Merck Suprapur and Merck $>99 \%$ respectively). Solutions for volumetric titrations were bought from Fluka $\left(0.10 \mathrm{M} \mathrm{NaOH}\right.$ and $\left.0.10 \mathrm{M} \mathrm{HNO}_{3}\right)$ and Roth $(0.010 \mathrm{M} \mathrm{NaOH})$ and used directly in the potentiometric titrations.

Solutions prepared from nitric acid (Merck Suprapur) and sodium hydroxide ( $0.1 \mathrm{M}$ standard, Merck) were used to adjust the $\mathrm{pH}$ when necessary. Potassium thiocyanide, hydrochloric acid, potassium chloride and ammonium acetate were all from Merck.

\subsection{Extraction and purification of $\mathbf{H A}$ sample}

Peat samples were collected in the Mogi River region of Ribeirão Preto, São Paulo State, Brazil. The humic substances were extracted following the IHSS procedure for soil organic matter ${ }^{[25]}$. The alkaline extracted (AE) soil HA was taken before the $\mathrm{HCl} / \mathrm{HF}$ treatment whereas the fully purified (FP) HA underwent the full purification procedure. In brief, the humic matter purification procedure for soils consists in separating the insoluble humin from the soluble humic and fulvic acids using a $1 / 10$ mass ratio of $0.1 \mathrm{M} \mathrm{NaOH}$ for $4 \mathrm{~h}$ under an inert atmosphere. This step is followed by acidification to $\mathrm{pH} 1 \mathrm{using} 1.0 \mathrm{M} \mathrm{HCl}$ to separate the soluble FA from the acid-insoluble HA. The $\mathrm{HA}$ is resuspended in $0.1 \mathrm{M} \mathrm{NaOH}$ and precipitated in $0.1 \mathrm{M} \mathrm{HCl} / 0.3 \mathrm{M} \mathrm{HF}$ to destroy the remaining mineral phase. Then, the solid is dispersed in water to form a slurry, and transferred to a Visking dialysis tube where it is subsequently dialysed against distilled water.

\subsection{Characterization of $\boldsymbol{H A}$ samples}

Both HAs (AE and FP) were characterised by UV-vis spectroscopy in the visible region. The absorption in $465 \mathrm{~nm}$ and $665 \mathrm{~nm}\left(\mathrm{E}_{4} / \mathrm{E}_{6}\right.$ ratio) was determined by dissolving $2.0 \mathrm{mg}$ of peat HA in 10 $\mathrm{mL}$ of $0.05 \mathrm{M} \mathrm{NaHCO}_{3}$, followed by measurement of the absorbance at 465 and $665 \mathrm{~nm}$ using a Hitachi U2000 spectrometer. The elemental composition $(\mathrm{C}, \mathrm{H}$ and $\mathrm{N})$ was determined using a Thermo Finnigan Flash EA 1112 elemental analyser. ${ }^{13} \mathrm{C}$ NMR analysis with crossed polarisation (CP) and magic angle spinning (MAS) was performed using a Bruker Avance III 400-MHz spectrometer, with a rotation of $5 \mathrm{kHz}$, contact time of $2 \mathrm{~ms}$, relaxation waiting time of $5 \mathrm{~s}$ and 11000 scans. Triplicate ash content determinations were performed by gravimetry, calcinating $1.0 \mathrm{~g}$ of sample at $6508 \mathrm{C}$ for $4 \mathrm{~h}$ using an oven from Magnus Fornos Lda (Brazil).

Total iron and aluminium contents after $\mathrm{HNO}_{3} / \mathrm{HF} / \mathrm{Hcl}$ digestion were determined by inductively coupled plasma atomic absorption spectroscopy (ICP-AES) (Thermo Fischer iCAP 6200 Duo). All analytical procedures were performed in triplicate for each sample. The standard reference material EnviroMAT SS-2 was acid-digested, then analysed using the same procedure as for the samples to check total metal content measurement accuracies, and the recoveries were within 93-105 $\%$ of expected values. Geochemically reactive 
metal present in the AE sample was extracted using a $0.43 \mathrm{M} \mathrm{HNO}_{3}$ extraction ${ }^{[26]}$ and concentrations were measured by ICP-AES and ICP-mass spectrometry (MS).

\subsection{Potentiometric titrations of HA samples}

All titrations were performed using a computercontrolled system under an argon atmosphere at $25{ }^{\circ} \mathrm{C}$. The organic matter concentration was 0.25 $\mathrm{g} \mathrm{L}^{-1}$ while the ionic strength $(I=0.01,0.03$, and $0.1 \mathrm{M}$ ) was fixed using $\mathrm{NaNO}_{3}$. The quoted $I$ are the initial values before the addition of any titrant. In data analyses, actual $I$ values were calculated for every data point, accounting for both background electrolyte ions and free $\mathrm{H}^{+}$and $\mathrm{OH}^{-}$. The $\mathrm{pH}$ of the solutions was controlled during titrations by addition of $0.1 \mathrm{M} \mathrm{HNO}_{3}$ and 0.1 and 0.01 $\mathrm{M} \mathrm{NaOH}$ solutions. The $\mathrm{pH}$ was recorded with a $\mathrm{pH}$ Hamilton Polilyte laboratory combined glass electrode (part no. 238403/02), calibrated by performing a blank titration of the background electrolyte before sample titration. The suspension was then titrated by adding small volumes of titrant, and the $\mathrm{pH}$ was recorded as a function of the titrant volume added to the suspension. After each addition, a drift criterion for $\mathrm{pH}$ was used $(\Delta \mathrm{mV}$ $\mathrm{min}^{-1}<0.1$ ) and a maximum time of 10 min was set for acquiring each data point. A similar procedure was followed for the blank solution titration. Three replicates were performed with fresh suspensions, in which each replicate was constituted by a forward and backward titration.

The same set-up was used to perform one-way titrations to estimate the functional group content of both AE and FP samples: samples were suspended in freshly prepared $0.1 \mathrm{M} \mathrm{NaNO}_{3}$ and titrated under an inert atmosphere between $\mathrm{pH} 3.5$ and 10 using $0.1 \mathrm{M} \mathrm{NaOH}$. Determination of carboxylic and phenolic content was done assuming that all carboxylic functional groups are neutralised at $\mathrm{pH}$ 8 , and that half of the phenolic groups are titrated between $\mathrm{pH} 8$ and $10^{[27]}$.

\subsection{Free metal determination in the presence} of humic matter: electrochemical experiments

The free metal ion concentration in the presence of the HAs was quantified using the AGNES electroanalytical technique. This technique enables direct determination of the free metal without the need for physical separation, while not being hampered by adsorption of $\mathrm{OM}$ at the electrode surface, giving a detection limit on the nanomolar range ${ }^{[28,29]}$.

An Ecochemie $\mu$ Autolab III and a PGStat 12 were used in conjunction with a Metrohm 663 VA stand (Metrohm, Switzerland). The set-up was controlled by GPES 4.9 software from EcoChemie (the Utrecht, Netherlands). A three-electrode configuration was used, comprising an $\mathrm{Hg}$ thin film plated onto a rotating glassy carbon disck (GC) (2$\mathrm{mm}$ diameter, Metrohm) as a working electrode ${ }^{[30]}$, and a DriRef-5 Ag/AgCl reference electrode from World Precision Instruments (electrolyte leakage $<810^{-4} \mathrm{~mL} \mathrm{~h}^{-1}$ ). A Denver Instrument (Model 15) and a Radiometer analytical combination $\mathrm{pH}$ electrode, calibrated with Titrisol buffers (Merck) were used to measure sample $\mathrm{pH}$.

Metal titrations of 5 to $100 \mathrm{mg} \mathrm{L}^{-1} \mathrm{HA}$ were performed at $I=0.01 \mathrm{M}$ and total metal concentrations in the interval from $10^{-7}$ to $510^{-6} \mathrm{M}$. $\mathrm{Cd}^{\mathrm{II}}$ and $\mathrm{Zn}^{\mathrm{II}}$ titrations were carried out at $\mathrm{pH} 6.0,7.0$ and 8.0, whereas $\mathrm{Pb}^{\mathrm{II}}$ titrations were carried out at $\mathrm{pH}$ 5.0, 6.0 and 6.5. Prior to each metal titration, a free metal calibration was performed. The limits of detection (LOD) calculated from the standard deviation of residuals $\left(3 \mathrm{~s}_{\mathrm{b}} / \mathrm{m} ; \mathrm{s}_{\mathrm{b}}\right.$ meaning standard deviation, $m$ meaning mean) for 12 different calibrations were in the interval 0.4 to $3.310^{-9} \mathrm{M}$ for $\mathrm{Cd}^{2+}, 1.4$ to $5.510^{-9} \mathrm{M}$ for $\mathrm{Pb}^{2+}$, and 1.4 to $6.010^{-9}$ $\mathrm{M}$ for $\mathrm{Zn}^{2+}$.

The measurements were performed applying the following sets of deposition potential $\mathrm{E}_{1}$ and deposition time $\mathrm{t}_{1}$ : Cd: $-0.68 \mathrm{~V}$ for $540 \mathrm{~s} ; \mathrm{Pb}:-0.48 \mathrm{~V}$ for $540 \mathrm{~s}$; Zn: $-1.1 \mathrm{~V}$ for $540 \mathrm{~s}$. The stripping step was performed with stripping chronopotentiometry using an oxidising current $I_{s}$ of $2 \times 10^{-6}$ A, applied until the potential reached $-0.30 \mathrm{~V}$. All solutions were purged for $15 \mathrm{~min}$ at the beginning of every experiment and for $20 \mathrm{~s}$ (assisted by mechanical stirring of the rotating electrode, 1000 rpm) after each measurement. All measurements were carried out at room temperature $\left(23^{\circ} \mathrm{C}\right)$. All measurements were performed in triplicate and no systematic variation was observed, indicating that chemical equilibrium was achieved in solution. 
2.6. Determining NICA-Donnan proton- and metal-binding parameters of FP sample

Material specific NICA-Donnan parameters for proton and metal binding for FP HA were determined using the PEST-ORCHESTRA tool ${ }^{[31]}$. The NICA-Donnan model distinguishes two different groups of binding sites, generally associated with carboxylic (Type 1 sites) and phenolic (Type 2 sites) functional groups. Non-specific electrostatic effects are taken into account with a Donnan model considering the humic particle as a permeable gel phase with a Donnan volume $V_{D}$ related to $I^{[13]}$. Here, we performed the optimisation using the relationship linking $V_{D}$ and $I$ through two parameters, $a$ and $b^{[32]}$, which according to Companys et al. ${ }^{[33]}$ in their comparison of the Donnan and non-linear Poisson-Boltzmann approaches, gives a good approximation of the electrostatic interaction of HA.

First, unconstrained parameterisation was performed on the potentiometric titrations dataset, and eight parameters were optimised: $a, b, Q_{\max , 1}$, $Q_{\mathrm{max}, 2}, \log K_{\mathrm{H}, 1}, \log K_{\mathrm{H}, 2}, m_{1}$ and $m_{2}{ }^{[31]} . Q_{\mathrm{max}, 1}$ and $Q_{\max , 2}$ are the proton site densities for the two considered groups of binding sites; $m_{1}$ and $m_{2}$ are the $n_{\mathrm{H}, 1} p_{1}$ and $n_{\mathrm{H}, 2} p_{2}$. In a second step, all parameters, except $m_{1}$ and $m_{2}$, were fixed, and proton-binding data were used together with $\mathrm{Cd}$ - and $\mathrm{Zn}$-binding data to optimise together $p_{1}, p_{2}\left(p_{1}\right.$ and $p_{2}$ are a measure of the widths of the affinity distributions,

which describes the intrinsic heterogeneity of the humic material), $n_{\mathrm{H}, 1}, n_{\mathrm{H}, 2}$ and the metal-binding parameters, $\log K_{\mathrm{Cd}, 1}, \log K_{\mathrm{Cd}, 2}, n_{\mathrm{Cd}, 1}, n_{\mathrm{Cd}, 2}$, lo$\mathrm{g} K_{\mathrm{Zn}, 1}, \log K_{\mathrm{Zn}, 2}, n_{\mathrm{Zn}, 1}$, and $n_{\mathrm{Zn}, 2}$. Last, the Pb-binding dataset was used to optimise the four $\mathrm{Pb}$-binding specific parameters $\left(\log K_{\mathrm{Pb}, 1}, \log K_{\mathrm{Pb}, 2}, \quad n_{\mathrm{Pb}, 1}\right.$ and $\left.n_{\mathrm{Pb}, 2}\right)$.

\section{Results and Discussion}

\subsection{Characteristics of FP and AE humic acids}

The comparison of the characteristics of both samples (Table S1, available as Supplementary material to this paper) provides information on the degree of humification and aromaticity of the material, which seems to be directly related to the metal binding ability of these substances ${ }^{[34]}$. Elemental analysis of soil purified HA gives values of ,50-60\% C, 3-6 \% H, 0.5-4\% N and 30-40\%
O. Although the FP is well within these ranges, it is clear that the carbon content of the $\mathrm{AE}(36.5 \%$ total or $39.6 \%$ ash-free) is well below the usual $50 \% \mathrm{C}$. The ${ }^{13} \mathrm{C}$ NMR results (Table S2) indicate that $\mathrm{HF} / \mathrm{HCl}$ attack followed by dialysis yielded a decrease of O-alkyl aromatic content and low $\mathrm{C}$ contents in the FP sample when compared with the AE. The results corroborate the variation in aromaticity shown by the spectroscopic $\mathrm{E}_{4} / \mathrm{E}_{6}$ ratio (Table S1) where ratios lower than 4 are indicative of a greater presence of condensed aromatic structures, whereas values greater than 4 indicate a lack of such structures ${ }^{[35]}$. More importantly, the carboxyl content of the FP is almost twice that of the AE, which should affect the metal-binding ability of these compounds. These results suggest that the purification procedure alters the structural characteristics of the extracted humic materials. ${ }^{[36]}$

The ash content difference between the two HAs (cf. Table S1: $\mathrm{AE}=7.9 \%$ v. $\mathrm{FP}=0.6 \%$ ) led us to perform an ICP-MS direct quantification and a $0.43 \mathrm{M} \mathrm{HNO}_{3}$ extraction (at 2, 4 and $48 \mathrm{~h}$ ) to evaluate the amount of $\mathrm{Al}$ and $\mathrm{Fe}$ present and extractable in the AE sample (Table 1). The results show that there is a considerable amount of $\mathrm{Al}$ and $\mathrm{Fe}$ in the AE sample, with 78 and $58 \% \mathrm{Al}$ and Fe recovery after a 48-h extraction. Other metals are present in negligible amounts, except for the $\mathrm{Na}$ remaining from the $\mathrm{NaOH}$ addition during the purification because the AE sample was not dialysed (Table S3).

Table 1. Total and extractable (0.43 $\left.\mathrm{M} \mathrm{HNO}_{3}\right) \mathrm{Al}$ and Fe concentrations in the alkaline extracted humic acid (AE HA) sample

$\begin{array}{lll}\text { Fractions } & \text { Al }\left(\mathrm{g} \mathrm{kg}^{-1}\right) & \text { Fe }\left(\mathrm{g} \mathrm{kg}^{-1}\right)\end{array}$

\begin{tabular}{ccc}
\hline Total & 24.9 & 2.5 \\
Extractable 2h & 16.7 & 1.37 \\
Extractable 4h & 17.4 & 1.32 \\
Extractable 48h & 19.4 & 1.44 \\
\hline
\end{tabular}

The X-ray powder diffraction (XRD) analysis (Fig. S1) showed the presence of a considerable amount of aluminosilicates (predominantly hal- 
loysite) but not iron minerals, indicating that the latter is probably amorphous iron or ionic iron strongly bound to the OM.

\subsection{Proton-binding characteristics of FP and} AE humic acids

Acid-base titrations at $0.01,0.03$ and $0.10 \mathrm{M} \mathrm{I}$ were performed for both FP (Fig. 1 and Table 2) and AE HAs. Both materials, particularly AE, showed poor titration repeatability (see Fig. S2) and a tendency to aggregate. Before performing a titration, the samples were dispersed at $\mathrm{pH} 10$ overnight under a nitrogen atmosphere. It is possible that some unstable and poorly crystallised oxides may dissolve and precipitate during titration in acidic and basic media respectively. This poor repeatability prevented us from obtaining sufficiently reliable protonation data for the $\mathrm{AE}$ sample.

For the FP, we obtained good NICA-Donnan model fits and Fig. 1 shows that when the charge of the FP is related to the $\mathrm{pH}$ in the Donnan gel instead of to the $\mathrm{pH}$ in solution, the curves for the different ionic strengths merge into a single master curve, indicating that the electrostatics are well accounted for using the Donnan volume equation with $a$ and $b$ parameters. ${ }^{[32]}$ The NICA parameters obtained are within the range of those reported previously by Milne et al. ${ }^{[36]}$ except for $\log K_{\mathrm{H}, 1}$ and $m_{1}$, which are slightly higher, probably owing to

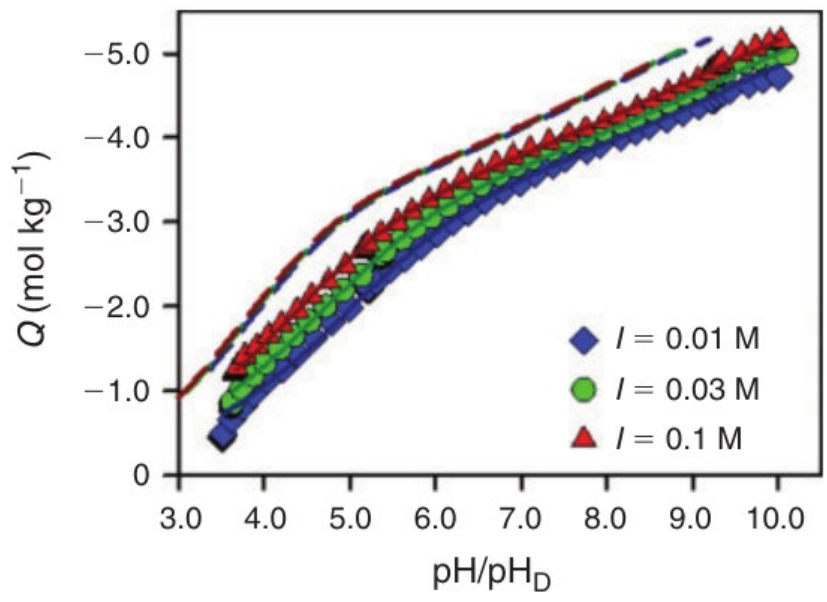

Fig. 1. Potentiometric titrations of fully purified humic acid (FP HA), at different I values: $0.01 \mathrm{M}$; $0.03 \mathrm{M}$; and $0.1 \mathrm{M}$ (adjusted with $\mathrm{NaNO}_{3}$ ).

Solid lines are fit results, whereas dashed lines are the charge when plotted against $\mathrm{pH}$ in the Donnan gel $\left(\mathrm{pH}_{D}\right)$ (master curve) (lines are coloured dark

blue, green and red accordingly with different coloured symbols for each I value).

the differences in the electrostatic fitting using a relationship between the Donnan volume and ionic strength with two parameters as compared with the one-parameter equation used by Milne.

To have a comparison between the two materials, we performed an end-point titration of both $\mathrm{AE}$ and $\mathrm{FP}$, which yielded values of 2.2 and 4.0 mol kg-1 of carboxylic groups (titrated between $\mathrm{pH}$

Table 2. Fitted set of NICA-Donnan parameters for proton and metal binding to fully purified humic acid (FP HA). Values in italics are from Milne et al. ${ }^{[37]} a$ and b, fitted set of NICA-Donnan parameters; $Q_{\max , 1}$ and $Q_{\max , 2}$, the proton site densities for the two considered groups of binding sites; $p_{1}$ and $p_{2}, a$ measure of the widths of the affinity distributions, which describes the intrinsic heterogeneity of the humic material

\begin{tabular}{|c|c|c|c|c|c|c|c|}
\hline \multicolumn{8}{|c|}{ FP HA-specific parameters } \\
\hline a & $\mathrm{b}$ & \multicolumn{2}{|c|}{$Q_{\max , 1}\left(\mathrm{~mol} \mathrm{~kg}^{-1}\right)$} & $p_{1}$ & \multicolumn{2}{|l|}{$Q_{\max , 2}\left(\mathrm{~mol} \mathrm{~kg}^{-1}\right)$} & $p_{2}$ \\
\hline \multirow[t]{2}{*}{$0.60 \pm 0.32$} & $-0.27 \pm 0.05$ & & & $0.79 \pm 0.03$ & $3.02 \pm 2.40$ & & $0.44 \pm 0.26$ \\
\hline & & & cific paramete & & & & \\
\hline Ion $\mathrm{i}$ & $\log \tilde{K}_{i, 1}$ & $n_{\mathrm{i}, 1}$ & $\log \tilde{K}_{i, 2}$ & $n_{\mathrm{i}, 2}$ & RMSE & $r^{2}$ & \\
\hline $\mathrm{H}$ & $3.65 \pm 0.23$ & $0.84 \pm 0.04$ & $8.07 \pm 0.77$ & $0.65 \pm 0.37$ & 0.05 & 0.99 & \\
\hline $\mathrm{Cd}$ & $1.79 \pm 0.10$ & $0.56 \pm 0.02$ & $2.49 \pm 1.30$ & $0.71 \pm 0.64$ & 0.07 & 0.98 & \\
\hline $\mathrm{Cd}^{[37]}$ & -0.2 & 0.73 & 2.37 & 0.54 & 0.14 & 0.97 & \\
\hline $\mathrm{Pb}$ & $3.44 \pm 0.11$ & $0.58 \pm 0.03$ & $4.14 \pm 1.78$ & $0.69^{\mathrm{A}}$ & 0.10 & 0.96 & \\
\hline $\mathrm{Pb}^{[37]}$ & 1.25 & 0.60 & 4.84 & 0.69 & 0.24 & 0.94 & \\
\hline $\mathrm{Zn}$ & $2.17 \pm 0.11$ & $0.69 \pm 0.05$ & $3.19 \pm 2.78$ & $0.27 \pm 0.14$ & 0.10 & 0.97 & \\
\hline $\mathrm{Zn}^{[37]}$ & 0.11 & 0.67 & 2.39 & 0.27 & 0.17 & 0.92 & \\
\hline
\end{tabular}

${ }^{\mathrm{A}}$ Generic value from Milne et al. ${ }^{[38]}$, value fixed in ORCHESTRA. 
3.7 and 8, and corresponding approximately to the $\left.Q_{\max , 1}\right)$ and values of 4.0 and $4.5 \mathrm{~mol} \mathrm{~kg}{ }^{-1}$ of phenolic groups respectively (twice the amount titrated between $\mathrm{pH} 8$ and 10, corresponding approximately to the $\left.Q_{\max , 2}\right)$. The FP values agree well with $Q_{\text {max }, 1}$ and $Q_{\text {max }, 2}$ obtained from the full titrations (Table 2). The AE shows approximately the same amount of phenolic groups as the FP but only half the amount of carboxylic groups, which agrees very well with the results obtained by NMR. Lopez et al. ${ }^{[23]}$ observed similar differences between the number of carboxylic sites of soil and purified HA fractions, which suggests that HF/ $\mathrm{HCl}$ treatment followed by the 8-kD dialysis may be responsible for this difference.

\subsection{Metal-binding parameters of FP $H A$}

The results of $\mathrm{Zn}$ binding to FP obtained in the present work are the first presented for very low concentrations of $\mathrm{Zn}$, with $\mathrm{p}[\mathrm{Zn}] 9$ to 7 . These concentrations are much lower than those in the two studies used to obtain the generic NICA-Donnan parameters, which are in the range $\mathrm{P}[\mathrm{Zn}] 4$ to 6. ${ }^{[37,38]}$ Moreover, these two datasets, one obtained by resin exchange experiments ${ }^{[39]}$ and one obtained using the Donnan Membrane Technique (DMT) but in the presence of significant $\mathrm{Ca}^{2+}$ competition $^{[40]}$, are small, having in total only 35 data points. The addition of the data points at low $\mathrm{p}[\mathrm{Zn}]$ will therefore aid in obtaining more reliable model parameters.
Fig. 2 depicts the experimental data and modelling results for the $\mathrm{Zn}, \mathrm{Cd}$ and $\mathrm{Pb}$ experiments at different $\mathrm{pH}$ values while Table 2 shows the optimised NICA-Donnan parameters. The $\log K_{\mathrm{H}, 1}$ is larger than the generic value (3.65 v. 2.93); hence, it is more appropriate to compare the difference between logarithm of bound metal $\left(\log K_{\mathrm{Me}, 1}\right)$ and the proton $\left(\log \mathrm{K}_{\mathrm{H}, 1}\right) \log K_{\mathrm{Me}, 1}-\log K_{\mathrm{H}, 1}$ rather than $\log K_{\mathrm{Me}, 1}$, which for $\mathrm{Zn}$ yields a binding constant for FP HA 20 times larger (1.3 log units) than the generic value. Similar differences are observed for the $\log K_{\mathrm{Me}, 1}$ of $\mathrm{Cd}$ and $\mathrm{Pb}$, with differences compared with the generic values of 1.3 and $1.5 \mathrm{log}$ units respectively. These differences are substantially larger than the variation in binding constants found so far. ${ }^{[41]}$ Electrostatic fitting using the $a$ and $b$ parameters instead of only one parameter yields a less acidic protonation constant, and concomitantly fewer metal ions bound in the Donnan phase in the acidic $\mathrm{pH}$ range $(\mathrm{pH}<6)$. Therefore, the metal stability constants need to be larger in order to fit the experimental data, as observed in Table 2.

The $n$ values for $\mathrm{Zn}$ are equal to the generic ones while the present $p_{1}$ value is significantly larger than the generic one $(0.79$ v. 0.62$)$ and $p_{2}$ is similar (0.44 v. 0.41).

The values obtained for Type 2 parameters have likely systematically larger errors than those for Type 1 parameters. This because with a $\log K_{\mathrm{H}, 2}$ of 8.1 , Type 2 sites should be largely protonated at

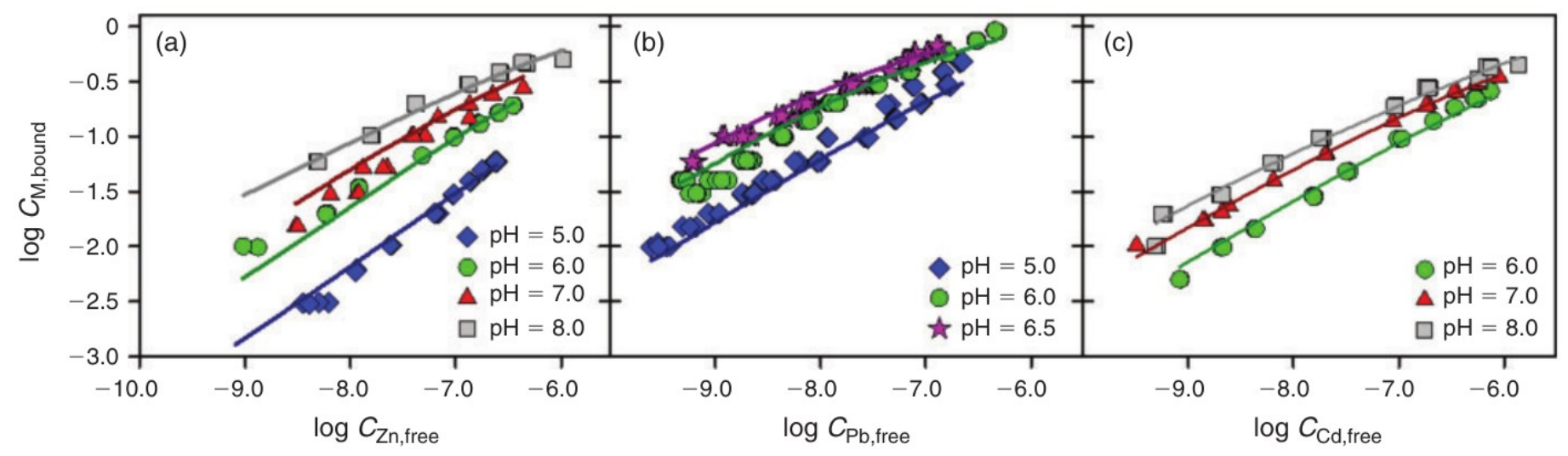

Fig. 2. Logarithm of bound metal concentration ((a) $\mathrm{Zn}$; (b) $\mathrm{Pb}$; (c) Cd) as a function of the logarithm of free metal concentration in the presence of fully purified humic acid (FP HA) determined by AGNES at ionic strength $I=0.01 \mathrm{M}$ (adjusted with $\mathrm{NaNO}_{3}$ ) at different $\mathrm{pH}$ values: 5.0; 6.0; 6.5; 7.0; and 8.0.

Solid lines are the optimisation results obtained by using the NICA-Donnan model (lines are coloured dark blue, green, pink, red and grey accordingly with different coloured symbols for each pH value). 
the $\mathrm{pH}$ values studied, yielding larger uncertainties in the optimised Type 2 parameters. This is probably the case for most published datasets.

\subsection{Comparison of metal-binding by FP and AE humic acids}

In this section, we compare the free metal concentrations measured for AE v. FP under the same experimental conditions. Fig. 3 for $\mathrm{Zn}$ and Figs S3 and $\mathrm{S} 4$ for $\mathrm{Cd}$ and $\mathrm{Pb}$ respectively show measured free metal concentrations in the presence of $\mathrm{AE}$ as a function of those measured in the presence of FP (blue symbols). The 1:1 line represents the same amount of free metal; thus, points above the line have more free metal (less complexation).

The binding experiments show on average , 1 order of magnitude higher free metal concentration for $\mathrm{AE}$ as compared with $\mathrm{FP}$ for $\mathrm{Zn}$ and $\mathrm{Cd}$ and $\sim 0.9 \log$ units higher for $\mathrm{Pb}$. This difference is more pronounced at lower metal-to-ligand (M/L) ratios and is smaller at higher $\mathrm{M} / \mathrm{L}$. This difference is similar for the three metals studied and independent of the $\mathrm{pH}$ within experimental error.

Part of these differences may be explained by the different carbon content of both materials (51.3\% for FP and $36.5 \%$ for AE; Table S1) associated with a different chemical composition. This is even more evident from the NMR results (Table S2) and endpoint titration data showing that the carboxyl content of the FP is approximately twice that of the AE. Metal binding by the AE sample may also be suppressed by interaction of $\mathrm{AE}$ with $\mathrm{Al}$ and $\mathrm{Fe}$ still present in the sample either in a mineral phase and as metal ions bound to the HA.

To investigate these hypotheses and their relative importance, we modelled the free metal concentrations in presence of FP for three scenarios using ORCHESTRA: (1) using the FP parameters as such (parameters from Table 2); (2) a scenario in which we reduced the value of $Q_{\max , 1}$ by $50 \%$ (to $1.59 \mathrm{~mol} \mathrm{~kg}^{-1}$ ) to evaluate the effect on metal binding of a lower amount of carboxylic groups as determined in the AE sample; and (3) a scenario in which we additionally considered the competition of $\mathrm{Al}$ and $\mathrm{Fe}$ as present in the AE sample as measured in the $0.43 \mathrm{M} \mathrm{HNO}_{3}$ extraction (Table 1, 48 h). Because no specific $\mathrm{Al}$ and $\mathrm{Fe}$ parameters are available for FP, we used their generic values in scenario 3 but scaled to the FP-specific proton parameters, thereby keeping the same relative strength of $\mathrm{Al}$ and $\mathrm{Fe}$ to proton binding. These metals were allowed to precipitate as ferrihydrite $(\log \mathrm{K}=3.19)$ or gibbsite $\left(\log \mathrm{K}_{\mathrm{so}}=8.29\right)$.

Simulated free metal concentrations for scenario 1 (Fig. 3 for $\mathrm{Zn}$ and Figs S3 and S4 for Pb and $\mathrm{Cd}$ respectively) are close to the 1:1 line. The small differences are due to both uncertainties in measurements and modelling. The reduction of the amount of carboxylic groups in scenario $2\left(Q_{\max , 1}\right)$ has a strong effect on the complexation. The simulations show a marked decrease in the difference between the measured free metal in the presence of $\mathrm{AE}$ and the modelled free metal in this scen-

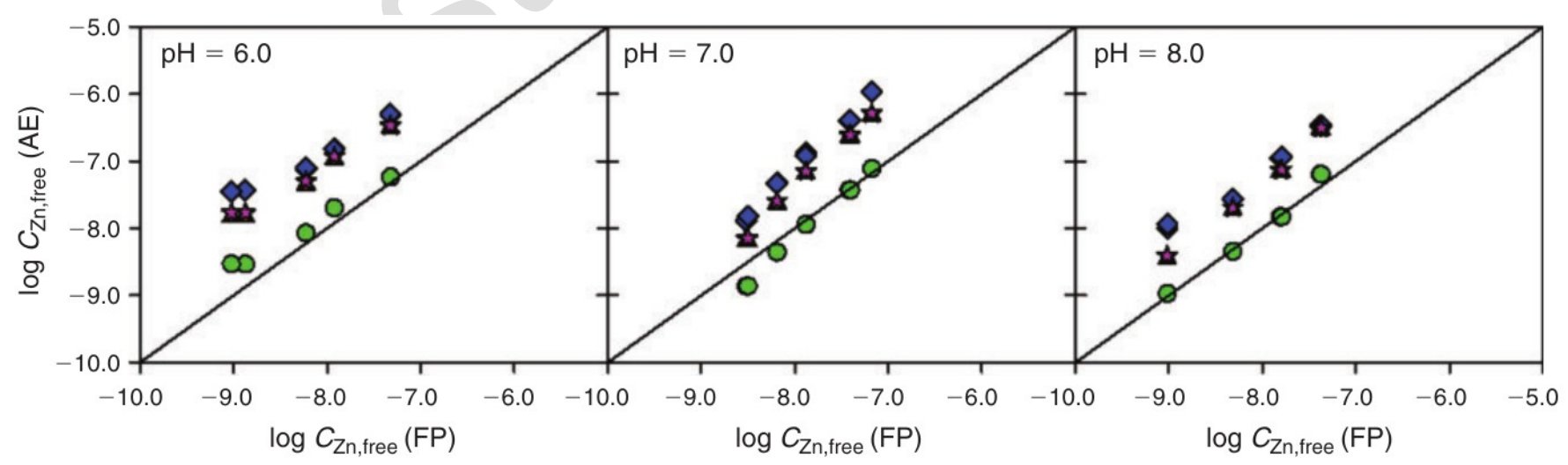

Fig. 3. Logarithm of free $\mathrm{Zn}^{2+}$ concentration in presence of alkaline extracted humic acid (AE HA) $v$. the logarithm of free $\mathrm{Zn}^{2+}$ concentration in the presence of fully purified (FP) HA for the same amount of organic material and at ionic strength $I=0.01 \mathrm{M}$ for $\mathrm{pH}$ 6.0, 7.0, and 8.0.

Symbols represent: $\diamond$ determined by AGNES; ofit results; $\triangle$ adjusted $Q_{1}$; s adjusted $Q_{1}$ with Al added. 
ario, which for $\mathrm{Zn}$ and $\mathrm{Cd}$ decreases on average from $\sim 1$ to $\sim 0.25-0.30$, and for $\mathrm{Pb}$ from 0.9 to $\sim 0.15$. For $\mathrm{Pb}$, the average reduction in the difference is somewhat misleading because for low $\mathrm{M} /$ $\mathrm{L}$, the difference is still significant but at high $\mathrm{M} / \mathrm{L}$ ratios, the difference disappears within experimental error. However, considering the competition of $\mathrm{Al}$ and $\mathrm{Fe}$ (scenario 3) has a negligible effect for $\mathrm{Cd}$, and very minor effects for both $\mathrm{Zn}$ and $\mathrm{Pb}$ of $\sim 0.02$ and $0.05 \log$ units respectively. Most of the difference in metal binding by FP can be explained by the larger number of carboxylic groups in the FP material.

\subsection{Implications for environmental impact as- sessments}

The results of this study indicate that the properties in terms of functional groups and aromaticity of humic materials present in OM are modified by the extraction and purification process and lead to increased metal binding by the fully purified material compared with alkaline extracted material. This implies that when applying ion-binding models for metal binding to OM that are parameterised based on purified HAs, metal binding is likely to be overestimated, and hence, bioavailability and mobility of metals may be underestimated. It is, however, common practice with the use of these models to consider only part of the OM being reactive in terms of a generic HA. This reactive fraction of soil OM is usually set at a fixed percentage between 30 and 100 by rule of thumb. ${ }^{[1]}$ The results of the present work show that when the number of carboxylic groups is reduced by 50 $\%$ to account for the difference between purified (FP) and the alkaline extracted material (AE) the predictions of metal binding to the more soil-like AE improves considerably. Regarding risk assessment studies, we demonstrate that it is indeed necessary to correct the $Q_{\max , 1}$ provided by the general parameters using a measured value or a factor of at least $50 \%$. Failing to do so will lead to underestimation of free metal concentration values for $\mathrm{Zn}, \mathrm{Cd}$ and $\mathrm{Pb}$ of one order of magnitude.

Our failure to obtain reproducible titrations of the $\mathrm{AE}$ material indicates that these fractions are not as stable as the FP material, which is already not particularly reproducible. The study of altern- ative extraction techniques, like physical extractions instead of chemical extractions and the standardisation of softer chemical extractions may help us to understand the changes that OM undergoes from the soil matrix to the solution One of these alternative methods is the replacement of the $\mathrm{HF} / \mathrm{HCl}$ treatment by a filtration step for the removal of mineral fractions recently proposed by the IHSS ${ }^{[25]}$, which we are planning to study in the near future.

This problem is interesting in itself and more so since Lehman and Kleber ${ }^{[42]}$ questioned the reality of what is called humics in soils and suggested the adoption of a soil continuum model, stating that alkaline extraction is not representative for soil OM. There is a clear need for further research on the nature of differences in the reactivity between purified v. less-disturbed natural OM, which will contribute to improved modelling of metal binding to $\mathrm{OM}$ in soils and other media, hence providing a basis for a more realistic risk assessment.

Conflicts of interest The authors declare that they have no conflicts of interest.

Acknowledgment. The authors acknowledge several institutions for financial support: (I) Coordenadoria de Aperfeiçoamento do Pessoal de Nivel Superior (CAPES; CSF scholarship 981313-6 to WGB and JPP); (ii) Conselho Nacional de Desenvolvimento Científico e Tecnológico (CNPq; PVE 400572/2013-3 visiting grant to JPP); (iii) the French national research agency (ANR; Blanc International II - SIMI 6 - Système Terre, Environnement, Risques SPECIES, and the national program 'Investissements d'avenir': ANR-10-LABX-21-01/LABEX RESSOURCES 21); (iv) the Portuguese national funding agency for science, research and technology (project no. FCT-ANR/AAG-MAA/0065/2012, SPECIES); (v) Region Lorraine who contributed to the postdoctoral contract of NJ.

\section{Supporting Information Available.}

\section{References}

[1] J. E. Groenenberg, S. Lofts, The use of assemblage models to describe trace element partitioning, speciation and fate: a review. Environ. Toxicol. Chem. 2014, 33, 2181. doi:10.1002/ETC.2642 
[2] L. T. C. Bonten, J. E. Groenenberg, H. Meesenburg, W. De Vries, Using advanced surface complexation models for modelling soil chemistry under forests. The Solling case. Environ. Pollut. 2011, 159, 2831. doi:10.1016/J.ENVPOL.2011.05.002

[3] E. Tipping, J. J. Rothwell, L. Shotbolt, A. J. Lawlor, Dynamic modelling of atmospherically deposited $\mathrm{Ni}, \mathrm{Cu}$, $\mathrm{Zn}, \mathrm{Cd}$ and $\mathrm{Pb}$ in Pennine catchments (northern England). Environ. Pollut. 2010, 158, 1521. doi:10.1016/J.ENVPOL.2009.12.026

[4] S. Thakali, H. E. Allen, D. M. Di Toro, A. A. Ponizovsky, C. P. Rodney, F. J. Zhao, S. P. McGrath, A terrestrial biotic ligand model. 1. Development and application to $\mathrm{Cu}$ and $\mathrm{Ni}$ toxicities to barley root elongation in soils. Environ. Sci. Technol. 2006, 40, 7085. doi:10.1021/ES061171S

[5] A. Duffner, L. Weng, E. Hoffland, S. van der Zee, Multisurface modeling to predict free zinc ion concentrations in low-zinc soils. Environ. Sci. Technol. 2014, 48, 5700. doi:10.1021/ES500257E

[6] ICMM, EuroMetaux, Defra, EURAS, MERAG Metals Environmental Risk Assessment Guidance 2007 (The International Council on Mining and Metals (ICMM): London).

[7] US EPA, Aquatic Life Ambient Freshwater Quality Criteria - Copper (2007 Revision) 2007 (US Environmental Protection Agency, Office of Water: Washington DC).

[8] A. J. Verschoor, J. P. A. Lijzen, H. H. van den Broek, R. F. M. J. Cleve, R. N. J. Comans, J. J. Dijkstra, P. H. M. Vermij, Kritische Emissiewaarden voor Bouwstoffen. Milieuhygienische Onderbouwing en Consequenties voor Bouwmaterialen 2006 (Rijksinstituutvoor Volksgezondheid en Milieu: Bilthoven).

[9] S. Lofts, E. Tipping, Solid-solution metal partitioning in the Humber rivers: application of WHAM and SCAMP. Sci. Total Environ. 2000, 251-252, 381. doi:10.1016/S0048-9697(00)00418-6

[10] D. G. Strawn, L. Baker, Speciation of $\mathrm{Cu}$ in a contaminated agricultural soil measured by XAFS, m-XAFS and m-XRF. Environ. Sci. Technol. 2008, 42, 37. doi:10.1021/ES071605Z

[11] E. Tipping, S. Lofts, J. E. Sonke, VII. Humic IonBinding Model: a revised parametrisation of cation-binding by humic substances. Environ. Chem. 2011, 8, 225. doi:10.1071/EN11016

[12] J. P. Gustafsson, Modeling the acid-base properties and metal complexation of humic substances with the Stockholm Humic Model. J. Col. Int. Sci. 2001, 244, 102. doi:10.1006/JCIS.2001.7871

[13] D. G. Kinniburgh, W. H. Van Riemsdijk, L. K. Koopal, M. Borkovec, M. F. Benedetti, M. J. Avena, Ion binding to natural organic matter: competition, heterogen- eity, stoichiometry and thermodynamic consistency. Colloids Surf. A. 1999, 151, 147. doi:10.1016/S09277757(98)00637-2

[14] J. P. Croué, M. F. Benedetti, D. Violleau, J. A. Leenheer, Characterization and copper binding of humic and non-humic organic matter isolated from the South Platte River: evidence for the presence of nitrogenous binding site. Environ. Sci. Technol. 2003, 37, 328. doi:10.1021/ ES020676P

[15] E. P. M. J. Fest, E. J. M. Temminghoff, R. N. J. Comans, W. H. van Riemsdijk, Partitioning of organic matter and heavy metals in a sandy soil: effects of extracting solution, solid to liquid ratio and $\mathrm{pH}$. Geoderma 2008, 146, 66. doi:10.1016/J.GEODERMA.2008.05.005

[16] H. Xue, L. Sigg, Comparison of the complexation of $\mathrm{Cu}$ and $\mathrm{Cd}$ by humic or fulvic acids and by ligands observed in lake waters. Aquat. Geochem. 1999, 5, 313. doi:10.1023/A:1009679819002

[17] E. Tipping, Cation Binding by Humic Substances 2002 (Cambridge University Press: Cambridge, UK).

[18] J. P. Gustafsson, D. B. Kleja, Modeling salt-dependent proton binding by organic soils with the NICA-Donnan and Stockholm Humic models. Environ. Sci. Technol. 2005, 39, 5372. doi:10.1021/ES0503332

[19] I. A. M. Ahmed, J. Hamilton-Taylor, S. Lofts, J. C. L. Meeussen, C. Lin, H. Zhang, W. Davison, Testing copper-speciation predictions in freshwaters over a wide range of metal-organic matter ratios. Environ. Sci. Technol. 2013, 47, 1487.

[20] J. J. Dijkstra, J. C. L. Meeussen, R. N. J. Comans, Evaluation of a generic multisurface sorption model for inorganic soil contaminants. Environ. Sci. Technol. 2009, 43, 6196. doi:10.1021/ES900555G

[21] D. G. Lumsdon, Partitioning of organic carbon, aluminium and cadmium between solid and solution in soils: application of a mineral humic particle additivity model. Eur. J. Soil Sci. 2004, 55, 271. doi:10.1111/J.13652389.2004.00599.X

[22] L. Weng, E. J. M. Temminghoff, W. H. Van Riemsdijk, Contribution of individual sorbents to the control of heavy metal activity in sandy soil. Environ. Sci. Technol. 2001, 35, 4436. doi:10.1021/ES010085J

[23] R. López, D. Gondar, J. Antelo, S. Fiol, F. Arce, Study of the acid-base properties of a peat soil and its humin and humic acid fractions. Eur. J. Soil Sci. 2012, 63, 487. doi:10.1111/J.1365-2389.2012.01461.X

[24] E. M. Thurman, R. L. Malcolm, Preparative isolation of aquatic humic substances. Environ. Sci. Technol. 1981, 15, 463. doi:10.1021/ES00086A012

[25] W. G. Botero, L. C. Oliveira, J. C. Rocha, A. H. Rosa, A. Santos, Peat humic substances enriched with nutrients for agricultural applications: competition between 
nutrients and non-essential metals present in tropical soils. J. Hazard. Mater. 2010, 177, 307. doi:10.1016/ J.JHAZMAT.2009.12.033

[26] J. E. Groenenberg, P. F. A. M. Römkens, A. van Zomeren, S. M. Rodrigues, R. N. J. Comans, Evaluation of the single dilute $(0.43 \mathrm{M})$ nitric acid extraction to determine geochemically reactive elements in soil. Environ. Sci. Technol. 2017, 51, 2246. doi:10.1021/ ACS.EST.6B05151

[27] E. M. Thurman, Organic Geochemistry of Natural Waters, 1985 (Springer: Amsterdam).

[28] J. Galceran, E. Companys, J. Puy, J. Cecilia, J. L. Garces, AGNES: a new electroanalytical technique for measuring free metal ion concentration. J. Electroanal. Chem. 2004, 566, 95. doi:10.1016/ J.JELECHEM.2003.11.017

[29] C. Parat, L. Authier, D. Aguilar, E. Companys, J. Puy, J. Galceran, M. Potin-Gautier, Direct determination of free metal concentration by implementing stripping chronopotentiometry as the second stage of AGNES. Analyst 2011, 136, 4337. doi:10.1039/C1 AN15481H

[30] L. S. Rocha, H. M. Carapuça, J. P. Pinheiro, Evaluation of nanometer-thick mercury film electrodes for stripping chronopotentiometry. J. Electroanal. Chem. 2007, 610, 37. doi:10.1016/J.JELECHEM.2007.06.018

[31] N. Janot, J. P. Pinheiro, W. G. Botero, J. C. L. Meeussen, J. E. Groenenberg, PEST-ORCHESTRA, a tool for optimising advanced ion-binding model parameters: derivation of NICA-Donnan model parameters for humic substances reactivity. Environ. Chem. 2017, 14, 31. doi:10.1071/EN16039

[32] M. F. Benedetti, W. H. van Riemsdijk, L. K. Koopal, Humic substances considered as a heterogeneous Donnan gel phase. Environ. Sci. Technol. 1996, 30, 1805. doi:10.1021/ES950012Y

[33] E. Companys, J. L. Garces, J. Salvador, J. Galceran, J. Puy, F. Mas, Electrostatic and specific binding to macromolecular ligands. A general analytical expression for the Donnan volume. Coll. Surf. A. 2007, 306, 2. doi:10.1016/J.COLSURFA.2007.01.016

[34] P. Tinoco, G. Almendros, F. J. González-Vila, J. Sanz, J. A. González-Pérez, Revisiting molecular characteristics responsive for the aromaticity of soil humic acids. J. Soils Sediments 2015, 15, 781. doi:10.1007/ S11368-014-1033-Y

[35] L. M. Neto, A. E. Andriulo, D. G. Traghetta, Effects of cultivation on ESR spectra of organic matter from soil size fractions of a Mollisol. Soil Sci. 1994, 157, 365. doi:10.1097/00010694-199406000-00005

[36] T. J. Tambach, H. Veld, J. Griffioen, Influence of $\mathrm{HCl} / \mathrm{HF}$ treatment on organic matter in aquifer sediments: a Rock-Eval pyrolysis study. Appl. Geochem. 2009, 24, 2144. doi:10.1016/J.APGEOCHEM.2009.09.004

[37] C. J. Milne, D. G. Kinniburgh, E. Tipping, Generic NICA-Donnan model parameters for proton binding by humic substances. Environ. Sci. Technol. 2001, 35, 2049. doi:10.1021/ES000123J

[38] C. J. Milne, D. G. Kinniburgh, W. H. van Riemsdijk, E. Tipping, Generic NICA-Donnan model parameters for metal ion binding by humic substances. Environ. Sci. Technol. 2003, 37, 958. doi:10.1021/ES0258879

[39] N. S. Randhawa, F. E. Broadbent, Soil organic matter-metal complexes: 6 . Stability constants of zinc-humic acid complexes at different $\mathrm{pH}$ values. Soil Sci. 1965, 99, 362. doi:10.1097/00010694-196506000-00002

[40] L. A. Oste, E. J. M. Temminghoff, T. M. Lexmond, W. H. van Riemsdijk, Measuring and modeling zinc and cadmium binding by humic acid. Anal. Chem. 2002, 74, 856. doi:10.1021/AC0105080

[41] J. E. Groenenberg, G. F. Koopmans, R. N. J. Comans, Uncertainty analyses of the non-ideal competitive adsorption-Donnan model: Effects of dissolved organic matter variability on predicted metal speciation in soil solution. Environ. Sci. Technol. 2010, 44, 1340. doi:10.1021/ES902615W

[42] J. Lehman, M. Kleber, The contentious nature of soil organic matter. Nature 2015, 528, 60. 